\title{
The Ties of Meeting Leaders: A Social Network Analysis
}

\author{
Nils Christian Sauer, Simone Kauffeld \\ Department for Industrial, Organizational and Social Psychology, Technische Universität Braunschweig, \\ Braunschweig, Germany \\ Email: $\underline{\text { n.sauer@tu-braunschweig.de }}$
}

Received 24 February 2015; accepted 11 March 2015; published 16 March 2015

Copyright (C) 2015 by authors and Scientific Research Publishing Inc.

This work is licensed under the Creative Commons Attribution International License (CC BY). http://creativecommons.org/licenses/by/4.0/

c) (i) Open Access

\begin{abstract}
This study extends meeting research by applying social network analysis to meeting leaders' behavior in actual, videotaped meetings $(\mathrm{N}=46)$ and examining the position of meeting leaders in the meeting network. Analyses reveal that meeting leaders are key players in meetings taking on the roles of central actor, broker, and elicitor. The role of central actor is linked to the number of planned actions during the meeting whereas the role of elicitor is associated with participants' satisfaction with the meeting leader and team productivity after the meeting. Our study highlights the different roles meeting leaders need to juggle to run meetings effectively.
\end{abstract}

\section{Keywords}

Meeting Leadership, Social Network Analysis, Meeting Roles, Key Players in Meetings

\section{Introduction}

Meetings are an important part of organizational life and used for a wide array of purposes (Cohen, Rogelberg, Allen, \& Luong, 2011). They are labor intensive and require the commitment of resources (Perkins, 2009). Overall, each hour spent in a meeting means less time for actual productive work (Leach, Rogelberg, Warr, \& Burnfield, 2009). Thus, meetings are often perceived as inefficient (Romano Jr. \& Nunamaker Jr., 2001). However, meetings remain a rarely studied facet of organizational behavior (Perkins, 2009; Rogelberg, Leach, Warr, \& Burnfield, 2006). As a result, questions remain about the factors that influence meeting effectiveness.

Meetings involve both content- and process-oriented behavior (Yukl, 2010). Researchers often mention procedural characteristics such as lack of structure and movement as well as missing focus and discipline as factors reducing meeting productivity (Carlozzi, 1999; Leach et al., 2009; Tobia \& Becker, 1990). Facilitation of the meeting process has been argued to be a key factor to increase the effectiveness of teams' goal-directed actions 
and their productivity (Bauer \& von der Reith, 2002; Kamp, 1999; Zaccaro, Rittman, \& Marks, 2001). When led by an expert meeting leader, meetings follow common, consistent patterns (Perkins, 2009) and participants feel more motivated and competent after well-run meetings (Bixler, 1991). A common strategy to achieve high meeting quality is thus to appoint a meeting leader tasked with overseeing the meeting process, controlling the flow of information, and encouraging contributions from all team members (Niederman \& Volkema, 1999; Schwarz, 2012). However, these recommendations are mostly based on literature for practitioners as the actual behavior and interaction in meetings has rarely been studied yet (Leach et al., 2009).

Research on meeting leadership has found that low attention to the meeting process is a central problem for effective meeting leadership (Brodbeck, Kerschreiter, Mojzisch, \& Schulz-Hardt, 2007; Perkins, 2009). Meetings with meeting leaders solely focusing on the content dimension have been shown to be less successful and have resulted in less meeting satisfaction (Perkins, 2009). However, past research on meeting leadership has mainly relied on anecdotal evidence and concentrated on describing meeting leaders' skills from a theoretical perspective (e.g., Perkins, 2009; Schwarz, 2012). More recently, studies have focused on technologies that are used as meeting assistants (Rienks, Nijholt, \& Barthelmess, 2009; Vivacqua, Marques, Ferreira, \& de Souza, 2008). By contrast, the study of meeting leaders' actual behavior in meetings has been neglected with only little empirical data addressing the problem (e.g., Malouff, Calic, McGrory, Murrell, \& Schutte, 2012; Remdisch, 1998). Despite recent calls for more research based on behavioral data (Baumeister, Vohs, \& Funder, 2007; Bonito \& Sanders, 2011), the question still remains as to how exactly meeting leaders behave in team meetings. Do they actually focus on the procedural dimension of the meeting? Do they structure the meeting? Do they elicit contributions?

Meeting leaders tasked with facilitating the meeting process are seen as meeting participants with a key role (Bauer \& von der Reith, 2002; Kamp, 1999; Malouff et al., 2012). We thus turn to a line of research that has a long history of analyzing key players in teams and organizations (Borgatti, 2006). Social network analysis has been used to identify key players in a broad range of different social situations. These scenarios can range from terrorist networks such as the 9/11 attacks (McGuire, 2011) to sports teams such as the recent Spanish national soccer team that won the World Cup in 2010 (Sarangi \& Unlu, 2010). Social network analysis offers several advantages in regard to the exploration of team meetings. It is used to explore social relations and interactions while accounting for social context (Balkundi \& Kilduff, 2006). The complexity of relations is captured by taking all relations between members of a network into account (Kilduff, Tsai, \& Hanke, 2005). As a result, the structure of interaction can be examined, which is of particular interest for the analysis of the role of meeting leaders because the social context of the meeting and the behavior of all meeting participants are taken into account (Bostrom et al., 1993).

Sauer and Kauffeld (2013) introduced a new approach to conceptualizing actual meeting behavior as an interaction network by using meeting participants' conversational responses as ties in the network. When a participant responds to a previous speaking-turn, a link connects the two speakers going from the participant making the first utterance to the participant reacting to it. Thereby, all interactions during the meeting are mapped onto a network and the interaction structure can be explored. Using actual meeting behavior to conceptualize meetings as an interaction network therefore provides a unique approach to study meeting leaders' roles by looking at their position in the network.

In the current study, we have three goals. First, we create meeting networks of 46 videotaped team meetings of work teams from two medium-sized German companies. We concentrate on meeting leaders from within the team that were elected by the team members. Analyzing their role in the meeting network, we build on literature on meeting leadership and communication networks by providing evidence regarding specific behavior in a natural work situation (Yukl, 2010). Following calls for more attention to natural work groups and behavioral data, we advance research on meeting leadership by comparing meeting leaders' recommended behaviors with their actual roles and actions in team meetings (Baumeister, Vohs, \& Funder, 2007; Bonito \& Sanders, 2011; Cummings \& Cross, 2003) and extend studies on communication networks beyond laboratory settings (Burgess, 1968; Shaw, 1964).

Second, we link meeting research with social network analysis and compute three network measures (outdegree centrality, weighted betweeness, and weighted assortativity) to examine meeting leaders' positions in meeting networks. Thereby, we contribute to small group research by exploring team members' structural position in the interaction of a team meeting (Katz, Lazer, Arrow, \& Contractor, 2004).

Third, we shed light on the unexplored link between meeting leaders' position in team meetings and meeting 
effectiveness by testing the influence of meeting leaders' position in the meeting network on the team outcomes of meeting leader satisfaction, planned actions during the meeting, and team productivity after the meeting (Leach et al., 2009).

In this article, we provide an overview of research on meeting leadership and social network analysis as a basis for our hypotheses. We then describe the process of conceptualizing meeting behavior as an interaction network and present our results. Finally, we conclude with a discussion of the implications meeting leaders' actual behavior in team meetings carries for team management and team training intervention.

\section{Theoretical Background}

\subsection{Leadership in Meetings}

Meetings are used to accomplish a wide range of goals such as pooling information, solving current work-related problems, and making decisions (Leach et al., 2009). This abundance of different functions complicates the management of the meeting process and creates a need for special meeting leadership (Malouff et al., 2012). The role of the meeting leader can be assumed by 1) a person external to the organization, 2) a person from within the organization but not from the team itself, or 3) a member of the particular team (Nelson \& MacFadzean, 1998). In each case, meeting leadership is seen as an executive function and is thus argued to be a leadership role (Bauer \& von der Reith, 2002; Yukl, 2010).

In literature on team meetings, a wide range of recommendations on leading meetings can be found (e.g. Haynes, 2006; Schwarz, 2012). The main role of meeting leaders is to manage the meeting process, move the meeting along, control the flow of information, and maintain a positive atmosphere (Carlozzi, 1999; Henkel, 2007; Rienks et al., 2009). Schwarz, Davidson, Carlson, and McKinney (2005) defined behavioral ground rules for meeting leaders which enable meeting participants to reach a common base of information, discuss differing points of view, and address underlying issues. These rules allow the meeting leader to adjust his behavior in a way that fosters productive collaboration between meeting participants. A critical part of the meeting leader's job is to encourage interchange between the meeting participants and trigger the communication necessary to reach mutual understanding within the group, to align the perception of current issues, to identify the nature of problems that need to be solved, and to find solutions for these problems (Jay, 1976; Kauffeld, 2006). Active participation has a positive effect on the participants because it increases consensus, promotes continued cooperation, and leads to higher performance and better quality decisions (Kelly \& Barsade, 2001; Korsgaard, Schweiger, \& Sapienza, 1995; Miranda \& Bostrom, 1999). Encouraging interchange also conveys a sense of being valued (Malouff et al., 2012). Specific executive practices in meetings such as participative communication are related to high-quality leader-member exchange (Yrle, Hartman, \& Galle, 2002) and have a positive influence on the willingness of team members to contribute during meetings (Baran et al., 2011; Wayne, Shore, Bommer, \& Tetrick, 2002). It has been shown that team members reciprocate fair treatment by team leaders with activity within the meeting (Lavelle, Rupp, \& Brockner, 2007). Participative communication by team leaders thus relates to team members' frequency of speaking up about issues, providing input, and creating an effective meeting environment (Baran et al., 2011).

Although research increasingly has highlighted the importance of leader behavior for team performance (DeRue, Nahrgang, Wellman, \& Humphrey, 2011; Druskat \& Wheeler, 2003), literature on meeting leadership has focused on two major facets so far. The first is the description of meeting leaders' competences and required behaviors (e.g., Haynes, 2006; Nelson \& McFadzean, 1998), and the second is the development and testing of the role of meeting assistants to improve meeting outcomes (Rienks et al., 2009; Vivacqua et al., 2008). There is, however, little evidence about which behaviors of meeting leaders influence positive meeting outcomes (Rogelberg et al., 2006; Perkins, 2009). Only a handful of studies have specifically examined the way meeting leaders manage actual meetings (e.g. Malouff et al., 2012). This research demonstrated that cooperation between meeting leaders and participants is important in achieving high meeting effectiveness (Remdisch, 1998). Even so, meeting leaders frequently engage in negative behaviors such as getting involved in power games with other team members (Hoering, Kühl, \& Schultze-Fielitz, 2001). Overall, in research on leader's actions in meetings, results have been not only scarce but also inconclusive. More empirical research on actual behavior during meetings is thus needed (Burke, Stagl, Salas, Pierce, \& Kendall, 2006; Perkins, 2009; Zaccaro et al., 2001).

\subsection{Key Positions in Meetings}

Meetings have been described as relationships between people, which are formed by participants' reactions to 1) 
interactions with other participants, 2) the content of the meeting, 3) interpersonal feelings, and 4) their own contributions (Bostrom et al., 1993). A meeting leader is tasked with influencing these relationships, which affect the role of each participant in the meeting. We thus argue that the detailed analysis of the relations between team members in the social setting of a team meeting is an important next step in the research of meeting leadership. Exploring the structural positions occupied by the meeting leader in the social system via social network analysis is crucial to verify the inconclusive evidence about meeting leaders' behavior in meetings (Perkins, 2009).

Social network analysis focuses on the relationships between actors instead of their attributes. The network approach explores actors' behavior embedded in the social context (Freeman, 2004; Uzzi, 1996). It has developed methods to analyze patterns of influence, interaction, and communication within social groups (Scott, 2000). The basic idea is that the connections between network members and the network structure predict group outcomes and group dynamics (Richardson, 2009).

Social network analysis hence provides tools to identify network positions that control the flow of information (e.g., Borgatti, 2006; Burt, 1992; Granovetter, 1973) and facilitate coordination between different parts of the network (e.g., Westphal, Seidel, \& Stewart, 2001). A wide range of different measures have been developed to identify key players in networks, which range from finding core and periphery members (e.g., Borgatti \& Everett, 1999) to measuring the social capital of network structures by identifying actors that fill structural holes (e.g., Burt, 1992; Coleman, 1990).

In early laboratory experiments, the relation between the communication structure of group discussions and perception of leadership, power, and group member satisfaction was analyzed (e.g., Guetzkow \& Simon, 1955; Leavitt, 1951; Shaw, 1955). Although most of the results were inconsistent, it was found that central participants were more active and more satisfied with the group performance. Moreover, they were perceived as leaders and organizers of the group (Goldberg, 1955; Mulder, 1959). Focusing on leadership styles, Fox (1957) examined group members' reactions to positive and negative leadership behavior. A positive leadership style was defined by behavior such as fostering interaction, encouraging group harmony and constructive compromise. A negative leadership style, by contrast, was defined by behavior such as imposing ideas, emphasizing authority, and utilizing group pressure. Results showed that a positive leadership style led to a more permissive group atmosphere, higher group member satisfaction with the group performance, and higher group member satisfaction with the leader's performance. Despite the encouraging results of these early experimental studies, recent research has focused on exploring the position of leaders in organizational networks (Kilduff, Tsai, \& Hanke, 2005) and showed that a leader's network is crucial for career success (Balkundi \& Kilduff, 2006; Burt, 2004). However, there is still little empirical work on leaders' social networks (Brass, Galaskiewicz, Greve, \& Tsai, 2004). As a result, in their review of different types of leadership networks, Hoppe and Reinelt (2010) identified two major issues for future leadership research: 1) how are leadership networks built and 2) how do network members communicate in these networks? In the current study, we expand on the second issue and analyze leaders' structural positions in meeting interaction.

\subsection{Leadership Ties in Meetings}

A new line of research has shown a way to conceptualize interaction in team meetings as a network, enabling the study of interaction structures with social network analysis (Sauer \& Kauffeld, 2013). In this approach, the network is shaped by meeting participants' conversational responses to previous actions. In the interaction network, the participants represent the actors, and the responses represent the ties. This way, the complete meeting interaction is displayed as a network (for a more thorough description of the meeting network see Sauer \& Kauffeld, 2013). This promising approach to team meetings can be used to explore the actual behavior of a meeting leader by analyzing the ties connecting meeting leader and meeting participants. In the current study, we examined the meeting leader's position in the meeting network to answer the following questions: Does the meeting leader occupy a central position in the team meeting? Does the meeting leader encourage interaction between the team members? Does the meeting leader elicit contributions from the team members? Does occupying a central position, encouraging interchange, and eliciting contributions have a positive effect on meeting effectiveness and team performance?

Building on early experiments on communication networks (e.g., Leavitt, 1951; Shaw, 1955), we concentrated on three network measures that relate to the meeting leaders' role in the meeting. The first network measure is degree centrality. An actor's centrality is the extent of ties that connect the actor with other actors in the 
network (Wasserman \& Faust, 1994). In a meeting, it describes how much a participant addresses others during the meeting. Research has shown that individuals with higher status participate more often in group discussions (Correll \& Ridgeway, 2003). Team members perceived as influential by the group show more participation and informal leaders frequently make the most contributions (Bass \& Stogdill, 1990; Dabbs \& Ruback, 1987; Wheelan \& Johnston, 1996). Meeting leaders are recommended to paraphrase participant's comments to facilitate communication by giving feedback (Shelton \& Bauer, 1994). They are also encouraged to summarize solutions and decisions, clarify questions, and test for consensus (Haynes, 2006; Mina, 2000; Perkins, 2009). As these tasks implicate a high number of speaking turns, we thus argue that meeting leaders have a central position in the meeting network.

Hypothesis 1a: Meeting leaders have a significantly higher outdegree centrality in the meeting network than team members.

The second network measure we examined is weighted betweeness. It measures the extent to which an actor brokers the links between others (Wasserman \& Faust, 1994). In meetings, it describes how much a team member brokers interchange between participants that are barely communicating with each other during the meeting (Balkundi \& Kilduff, 2006). Betweeness has become an important measure in the analysis of leader networks as a predictor for the emergence of leadership (e.g., Brass, 1984). A meta-analysis found that actors with high betweenness centrality in communication networks are perceived as leaders (Mullen \& Salas, 1991). The role of broker that bridges between different parts of the network is a key factor for leaders to be successful as it helps coordinate activities and control the flow of information (Hoppe \& Reinelt, 2010). As argued above, the coordination of interaction and encouragement of interchange is an important part of managing the meeting process (Schwarz et al., 2005). It is thus crucial for a meeting leader to be a broker in the meeting network and forge links between unconnected team members.

Hypothesis 1b: Meeting leaders have a significantly higher betweeness centrality in the meeting network than meeting participants.

The third network measure we examined is weighted assortativity. It represents how strongly a central actor is connected to other central actors in the network (Leung \& Chau, 2007). In a meeting, it describes the tendency of a central meeting participant to interact with other central participants. A meeting leader's task is to encourage meeting participants to contribute and share their expertise. A key to forge successful coalitions is the identification of suitable collaborators by finding structural holes in networks that can be bridged (Janicik \& Larrick, 2005). Meeting leaders need to identify reluctant and quiet team members and integrate them in the discussion to tap their knowledge for the rest of the team. Thus, meeting leaders need to address decentral team members and have a strong connection to them. As we presume that meeting leaders have a central position in the meeting network, we hypothesize that they interact significantly more with decentral team members than the other participants do. Meeting leaders thus have a lower assortativity.

Hypothesis 1c: Meeting leaders have a significantly lower weighted assortativity in the meeting network than team members.

\subsection{Leaders' Position and Success of Meetings}

The goal of meetings is to share information, make decision and find specific solutions for work problems (e.g. Leach et al., 2009; Volkema \& Niederman, 1995). Unmanaged interaction, however, often leads to ineffective communication and poor decision-making (Lehmann-Willenbrock, Allen, \& Kauffeld, 2013; Sunwolf \& Frey, 2005). Schultz and Kretow (1996) analyzed the role of the "critical reminder" who was tasked with helping groups come to more effective decisions and found that assigning this role to a group member led to higher quality decisions. Research also showed that assigning a meeting leader to coordinate the meeting process is a central factor for meeting productivity (Carlozzi, 1999; Malouff et al., 2012; Sisco, 1993). However, studies on the impact of the meeting process on meeting effectiveness and team outcomes are still sparse (Rogelberg et al., 2010). As argued above, coordinating the meeting process is the meeting leaders' task which comprises guiding the communication, synchronizing participants, and encouraging contributions. Previous research has shown that a central position in communication networks is important for leaders to be successful. It helps them dispense information and steer the team towards a common goal in meetings (Friedkin \& Slater, 1994). It allows them to run highly-structured meetings which fosters participants' goal focus, attainment of objectives, and task implementation (Carlozzi, 1999; Putnam, 1983; Sunwolf \& Seibold, 1999). These findings suggest that it is cru- 
cial for meeting leaders to have a central position for meetings to be effective. High-betweeness actors have been found to be important in communication networks to coordinate the interaction. Synchronizing participants' actions is a critical factor for meetings to be perceived as effective (Lehmann-Willenbrock et al., 2013). The brokering of interchange between meeting participants can thus be seen as crucial for meeting effectiveness. Communication research has found that encouraging participants to contribute to the interaction is a key factor for meetings to be productive (Malouff et al., 2012). Furthermore, decentralized interaction in meetings is associated with team performance (Sauer \& Kauffeld, 2013). Involving all participants in the meeting interaction can thus be seen to positively influence meeting effectiveness. As argued above, meetings are perceived as effective if decisions were made and actions were set to be carried out after the meeting (Kauffeld \& Lehmann-Willenbrock, 2012). We therefore expect meeting leaders' actions of guiding the meeting, coordinating the interaction, and encouraging contributions to have a positive effect on actions set during the meeting.

Hypothesis 2a: Meeting leaders' outdegree centrality and weighted betweeness are positively and weighted assortativity is negatively related to the number of actions set during the meeting.

Beyond the influence on meeting effectiveness, it has been argued that the interaction in team meetings can be seen as a manifestation of team performance. Van Praet (2009) argues that a meeting leader who supervises the meeting process and gives encouragement is important to motivate participants and achieve high team performance. In line with this reasoning, laboratory experiments showed that leadership behavior of facilitating interaction and compromise is related to high perception of group performance (Fox, 1957). Recent studies have shown that procedural meeting communication, such as task structuring and action planning, is linked to team productivity after the meeting (Kauffeld \& Lehmann-Willenbrock, 2012; Mesmer-Magnus \& DeChurch, 2009). Moreover, there is ample research that demonstrates the influence of leaders' position in interaction networks on team performance. Groups in which the leaders occupy a central position in the network perform better (e.g., Balkundi \& Harrison, 2006). Synchronizing actions between team members' has a positive effect on team performance (e.g., Malouff et al., 2012). Groups in which all members participate evenly in their communication are associated with higher group performance (e.g., Bonito \& Hollingshead, 1997). We thus expect meeting leaders' actions of guiding the meeting, coordinating the interaction, and encouraging contributions to have an influence beyond meeting effectiveness and positively affect team performance after the meeting.

Hypothesis 2b: Meeting leaders' outdegree centrality and weighted betweeness are positively and weighted assortativity is negatively related to team productivity.

Finally, we are interested in the link between meeting leaders' position in the interaction network and participants' evaluation of their performance. We therefore investigate participants' satisfaction with the meeting leader. Previous experiments found that leadership behavior, such as encouraging interaction and group unity, is related to higher team member satisfaction with the leader's performance (Fox, 1957). Recent field studies showed that procedural meeting behavior is a key factor to achieve high meeting satisfaction (Kauffeld \& Lehmann-Willenbrock, 2012). The way meetings are run shapes the way the meeting leader is perceived by the participants (Perkins, 2009). Badly-run meetings can lead to negative employee attitudes, such as job dissatisfaction, whereas well-run meetings make employees feel competent and motivated (Bixler, 1991; Rogelberg et al., 2006). Malouff and colleagues (2012) found that the encouragement of participation by the meeting leader is particularly important for high meeting satisfaction. These results give ground for expecting that a meeting leader effectively guiding the meeting process by enabling all participants to contribute and be fully involved in the interaction leads to more participants being satisfied with the meeting leader's performance.

Hypothesis 2c: Meeting leaders' outdegree centrality and weighted betweeness are positively and weighted assortativity is negatively related to patricipants' satisfaction with the meeting leader.

\section{Method}

\subsection{Sample}

We conducted a field study to explore the role and position of meeting leaders in meetings. There were 46 teams from two medium-sized German organizations from the automotive supply and high-voltage technology industries in the sample. All teams were specialized in assembly or manufacturing tasks. Meetings were held each week for an hour to talk about current, work-related topics. A meeting leader discussed optimization tasks with three to six meeting participants. 


\subsubsection{Meeting Leaders}

The sample was comprised of 46 meeting leaders. Their age ranged from 19 to 58 years with an average age of 33.74 years $(S D=9.32)$. There were only three female meeting leaders in the sample. Meeting leaders were regular team members who were elected by the group as team representatives. They received two days of training to prepare them for their role of team representative. The training comprised the topics team work, conflict management, presentation, and moderation techniques. The emphasis, however, was on team work and conflict management. By comparison, there was only a two hour briefing on moderation techniques during the training. The meeting leaders thus had basic knowledge of meeting moderation but were neither specifically trained in managing the meeting process nor did they have information regarding specific meeting roles.

\subsubsection{Meeting Participants}

The sample was comprised of 236 meeting participants. Their age ranged from 19 to 59 years with an average age of 36.76 years $(S D=11.33)$. As is representative of the particular industries examined, the majority of participants was male (8.8\%).

\subsection{Procedure}

Interaction data were collected during regular team meetings taking place approximately once a month. The teams discussed a current work-related topic with no supervisor present. The team meetings were videotaped with the participants being advised to ignore the camera and behave as they would under normal circumstances. When asked afterwards, all the discussions were characterized as typical for this kind of meeting by all teams.

For analysis of the videotaped interaction data, speaking-turns were coded with INTERACT software (Mangold, 2010). A pool of five trained coders who were unaware of the research question was used. Each speakingturn was cut from the video stream, enumerated and assigned to a team member.

\subsection{Meeting Network}

To conceptualize the videotaped team meetings as interaction networks, participants' conversational responses to previous actions are used as the ties in the meeting network in this approach (Sauer \& Kauffeld, 2013). The participants represent the nodes, and the responses represent the ties. When, for example, the meeting leader makes a statement and another participant responds to it, a tie connects them. When the participant's speaking-turn follows the meeting leader's turn, an arrow from the meeting leader to the participant illustrates who reacted to whom. This way, all speaking-turns in the meeting are counted and coded as arrows in the network. As a result, the meeting network displays who reacted to whom with which frequency as the connecting ties are valued and directed (for a more thorough description of the meeting network, see Sauer \& Kauffeld, 2013).

\subsection{Measures}

\subsubsection{Outdegree Centrality}

The measure of degree centrality describes the number of ties an actor has in the network (Wasserman \& Faust, 1994). Outdegree centrality is seen as a measure of how influential an actor is in the network (Borgatti, Mehra, Brass, \& Labianca, 2009) and represents a participants' number of conversational turns which are followed by another participant's response. It was calculated as participants' number of speaking-turns proportional to the overall sum of speaking-turns in the meeting using the tnet package 3.0.11 in R (Opsahl, 2009). Figure 1 shows the meeting network of a team meeting with a meeting leader as the most central actor.

\subsubsection{Weighted Betweeness Centrality}

The measure of weighted betweeness centrality describes the extent to which an actor funnels information among the other actors in the network. In meeting interaction, it describes the extent of control an actor exerts over the information flow. The betweeness centrality was calculated using the tnet package 3.0.11 in R (Opsahl, 2009). Figure 2 shows the meeting network of a team meeting with the meeting leader as a broker with a high weighted betweeness score.

\subsubsection{Weighted Assortativity}

The measure of weighted assortativity describes the extent to which a central actor has a strong connection to 
other central actors in the network (Leung \& Chau, 2006). In meeting interaction, it describes the tendency of central participants to mostly interact with other central participants who are also heavily involved in the discussion. The weighted assortativity coefficient was calculated using the igraph package $0.6 .5-2$ in $\mathrm{R}$ (Csardi \& Nepusz, 2006). Figure 3 shows the meeting network of a team meeting with a meeting leader who has a low assortativity and is strongly connected with decentral participants.

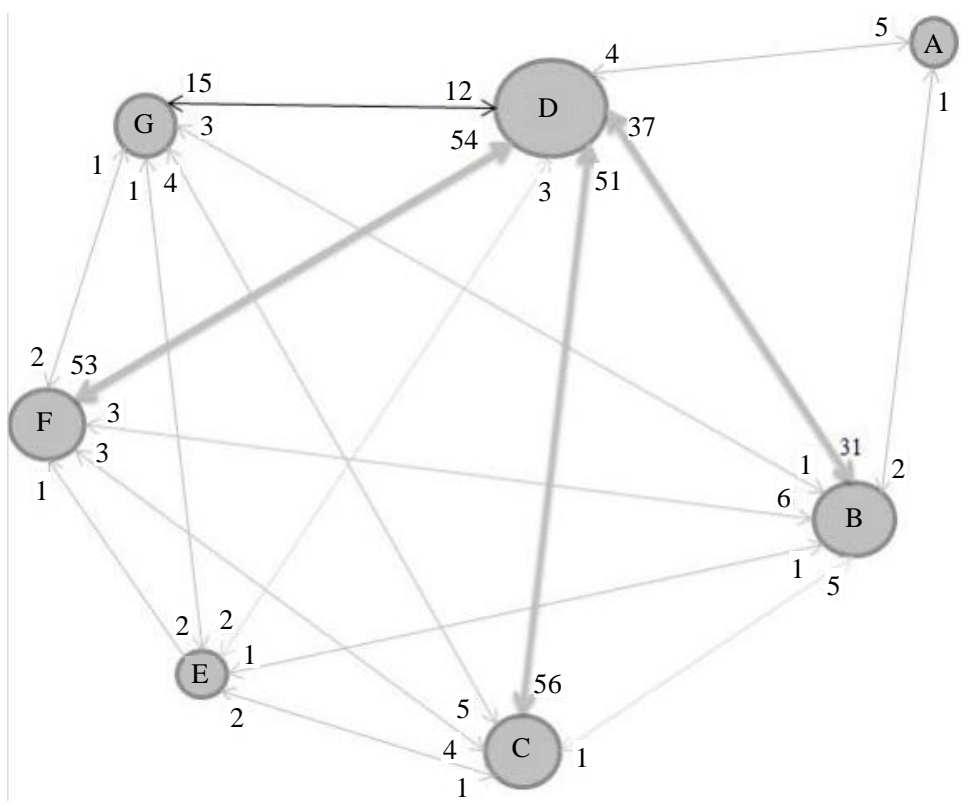

Figure 1. Outdegree centrality: Sociogram of a team meeting with a meeting leader (D) with high outdegree centrality (Cdeg $+(v)=.43)$. Arrows display the link from a meeting participant making an utterance to a participant responding to it; numbers at incoming arrows display numbers of responses; thickness of arrows represents relative number of responses.

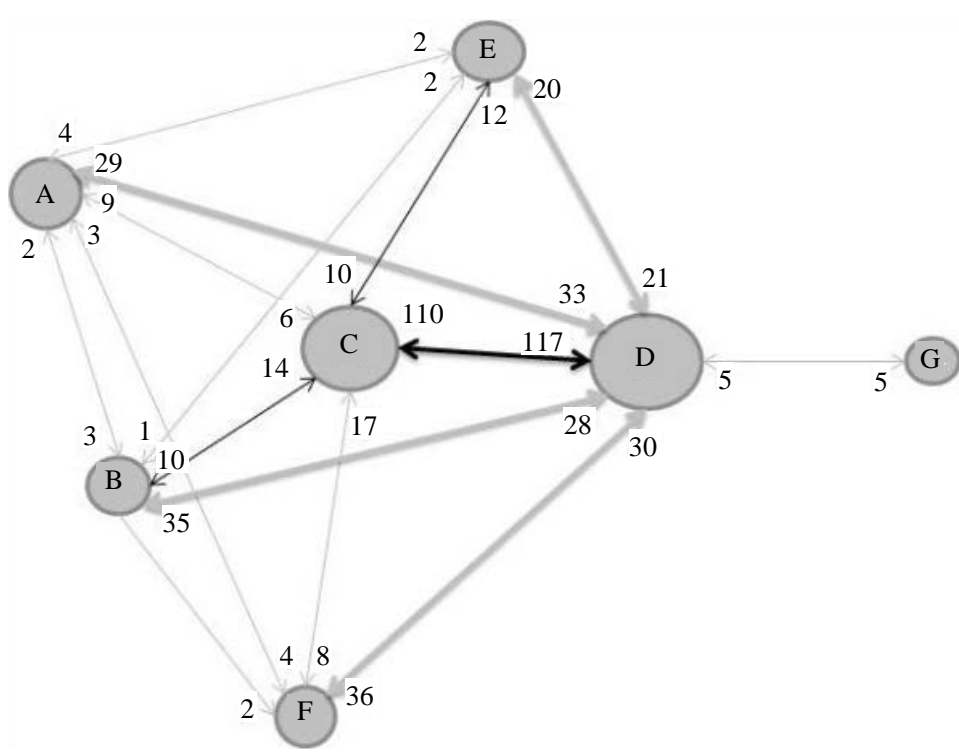

Figure 2. Weighted betweeness: Sociogram of a team meeting with a meeting leader (D) with high weighted betweeness $(\mathrm{CB}(\mathrm{v})=30)$. Arrows display the link from a meeting participant making an utterance to a participant responding to it; numbers at incoming arrows display numbers of responses; thickness of arrows represents relative number of responses. 


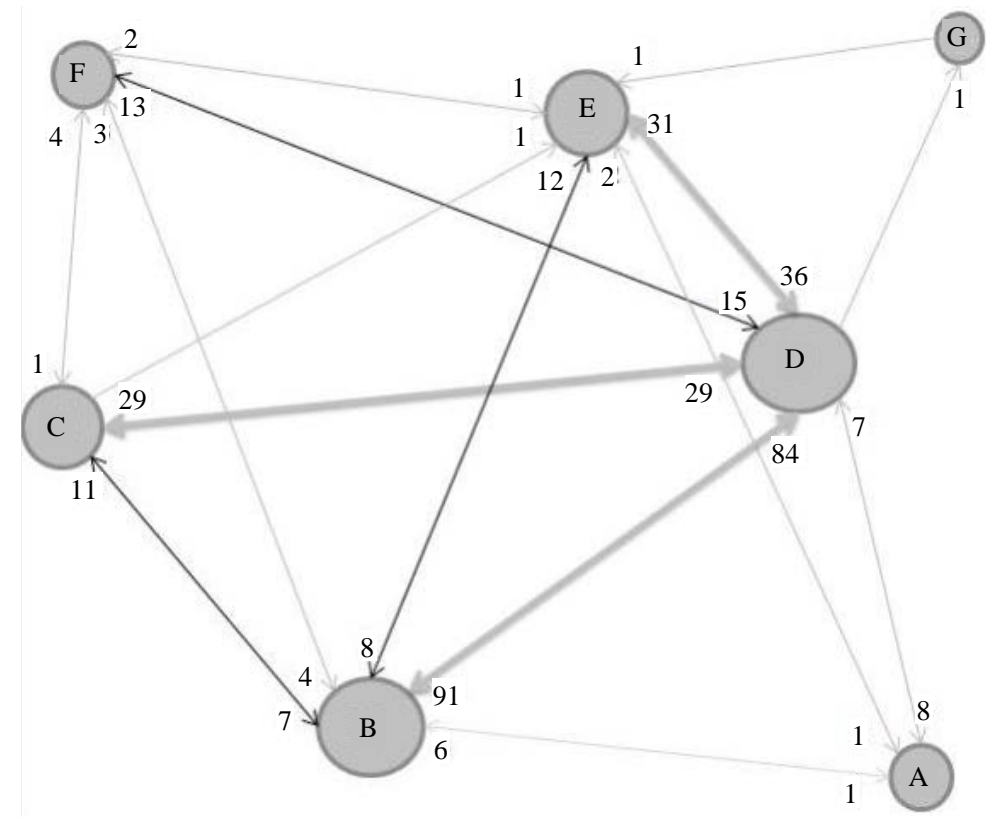

Figure 3. Weighted assortativity: Sociogram of a team meeting with a meeting leader (D) with low weighted assortativity (knn, $i=2.76)$. Arrows display the link from a meeting participant making an utterance to a participant responding to it; numbers at incoming arrows display numbers of responses; thickness of arrows represents relative number of responses.

\subsubsection{Planned Actions}

The videotaped interaction data was used to code how many actions were set during the meeting to be carried out subsequently. An action was defined as a measure that was mapped out (who will do what next) and planned (by when will it be carried out). The number of planned actions were counted for each team meeting. Two coders who were unaware of the research question were used. As recommended by Bakeman and Quera (2011), we calculated the strict measure of absolute ICC to test inter-rater-reliability for two coders. Results show an excellent inter-rater-reliability $(I C C=.96 ; p<.01)$.

\subsubsection{Team Productivity}

Objective productivity data were provided by the management of the two organizations on a team level for 32 teams. Productivity numbers were defined as the planned minus the actual production for the year after the team meeting.

\subsubsection{Meeting Leader Satisfaction}

Participants of 43 team meetings were asked to give a team-rating of their satisfaction with the meeting leader using a 9-point answering format. Due to time constraints, it was not possible to collect the data for every meeting. The questionnaire comprised eleven items regarding the meeting leader's performance during the meeting. Reliability analysis showed a Cronbach's alpha of $\alpha=.92$. All items are represented in Table 1.

\section{Results}

Means, standard deviations, and intercorrelations between all variables are presented in Table 2.

We performed t-tests to analyze differences between team leaders and members in terms of socio-demographic characteristics. Results show that there are no significant differences for age $(t=1.84, p=.07)$ and gender $(t=1.66, p=.10)$ between meeting leaders and participants.

In hypotheses 1a, 1b, and 1c, the network positions of the meeting leaders and participants were compared. These network data do not satisfy the assumptions of independence as each actor's individual position in the network incorporates information about the position of other actors. 
Table 1. Questionnaire items.

1) The meeting leader is dedicated to managing the meeting.
2) The meeting leader is accepted by the group.
3) The meeting leader proceeds in a structured manner.
4) The meeting leader entirely dispenses information.
5) The meeting leader pushes for suggestions from the group.
meeting leader
$\begin{aligned} & \text { 6) The meeting leader encourages contributions. } \\ & \text { 8) The meeting leader emphasizes team work. } \\ & \text { 9) The meeting leader mediates in cases of conflicts. } \\ & \text { 10) The meeting leader carries out his role. } \\ & \text { 11) The meeting leader fulfills the demands of managing the meeting. }\end{aligned}$

Table 2. Means, standard deviations, Cronbach’s alpha and pearson’s correlations between measurement variables.

\begin{tabular}{|c|c|c|c|c|c|c|c|c|c|c|}
\hline Variable & $\mathrm{M}$ & SD & (1) & (2) & (3) & (4) & (5) & (6) & (7) & (8) \\
\hline 1) Outdegree centrality & $\begin{array}{c}.29 \\
(\mathrm{~N}=46)\end{array}$ & $\begin{array}{c}.09 \\
(\mathrm{~N}=46)\end{array}$ & & & & & & & & \\
\hline 2) Weighted beetweeness & $\begin{array}{c}11.41 \\
(\mathrm{~N}=46)\end{array}$ & $\begin{array}{c}9.90 \\
(\mathrm{~N}=46)\end{array}$ & $\begin{array}{c}.61^{* *} \\
(\mathrm{~N}=46)\end{array}$ & & & & & & & \\
\hline 3) Weighted assortativity & $\begin{array}{c}8.06 \\
(\mathrm{~N}=46)\end{array}$ & $\begin{array}{c}11.75 \\
(\mathrm{~N}=46)\end{array}$ & $\begin{array}{c}-.39^{* *} \\
(\mathrm{~N}=46)\end{array}$ & $\begin{array}{c}-.38^{* *} \\
(\mathrm{~N}=46)\end{array}$ & & & & & & \\
\hline 4) Planned actions & $\begin{array}{c}4.02 \\
(\mathrm{~N}=46)\end{array}$ & $\begin{array}{c}2.49 \\
(\mathrm{~N}=46)\end{array}$ & $\begin{array}{c}.57^{* *} \\
(\mathrm{~N}=46)\end{array}$ & $\begin{array}{c}.32^{*} \\
(\mathrm{~N}=46)\end{array}$ & $\begin{array}{c}-.42^{* *} \\
(\mathrm{~N}=46)\end{array}$ & & & & & \\
\hline 5) Team productivity & $\begin{array}{c}-.07 \\
(\mathrm{~N}=32)\end{array}$ & $\begin{array}{c}.77 \\
(\mathrm{~N}=32)\end{array}$ & $\begin{array}{c}.11 \\
(\mathrm{~N}=32)\end{array}$ & $\begin{array}{c}-.23 \\
(\mathrm{~N}=32)\end{array}$ & $\begin{array}{c}-.40^{*} \\
(\mathrm{~N}=32)\end{array}$ & $\begin{array}{c}-.06 \\
(\mathrm{~N}=32)\end{array}$ & & & & \\
\hline $\begin{array}{l}\text { 6) Satisfaction with the } \\
\text { meeting leader }\end{array}$ & $\begin{array}{c}7.21 \\
(\mathrm{~N}=43)\end{array}$ & $\begin{array}{c}.99 \\
(\mathrm{~N}=43)\end{array}$ & $\begin{array}{c}.24 \\
(\mathrm{~N}=40)\end{array}$ & $\begin{array}{c}.00 \\
(\mathrm{~N}=40)\end{array}$ & $\begin{array}{c}-.50^{* *} \\
(\mathrm{~N}=40)\end{array}$ & $\begin{array}{c}.25 \\
(\mathrm{~N}=40)\end{array}$ & $\begin{array}{c}.40^{*} \\
(\mathrm{~N}=31)\end{array}$ & $(.92)$ & & \\
\hline 7) Group size & $\begin{array}{c}6.24 \\
(\mathrm{~N}=46)\end{array}$ & $\begin{array}{c}.92 \\
(\mathrm{~N}=46)\end{array}$ & $\begin{array}{c}-.14 \\
(\mathrm{~N}=46)\end{array}$ & $\begin{array}{c}.46^{* *} \\
(\mathrm{~N}=46)\end{array}$ & $\begin{array}{c}.17 \\
(\mathrm{~N}=46)\end{array}$ & $\begin{array}{c}-.18 \\
(\mathrm{~N}=46)\end{array}$ & $\begin{array}{c}-.58^{*} \\
(\mathrm{~N}=32)\end{array}$ & $\begin{array}{c}-.22 \\
(\mathrm{~N}=40)\end{array}$ & & \\
\hline 8) Gender distribution & $\begin{array}{c}12.52 \\
(\mathrm{~N}=46)\end{array}$ & $\begin{array}{c}21.62 \\
(\mathrm{~N}=46)\end{array}$ & $\begin{array}{c}.00 \\
(\mathrm{~N}=46)\end{array}$ & $\begin{array}{c}.14 \\
(\mathrm{~N}=46)\end{array}$ & $\begin{array}{c}-.09 \\
(\mathrm{~N}=46)\end{array}$ & $\begin{array}{c}.07 \\
(\mathrm{~N}=46)\end{array}$ & $\begin{array}{c}-.30 \\
(\mathrm{~N}=32)\end{array}$ & $\begin{array}{c}-.05 \\
(\mathrm{~N}=40)\end{array}$ & $\begin{array}{c}.29 \\
(\mathrm{~N}=46)\end{array}$ & \\
\hline 9) Participants' age & $\begin{array}{c}35.97 \\
(\mathrm{~N}=45)\end{array}$ & $\begin{array}{c}5.82 \\
(\mathrm{~N}=45)\end{array}$ & $\begin{array}{c}-.23 \\
(\mathrm{~N}=45)\end{array}$ & $\begin{array}{c}.02 \\
(\mathrm{~N}=45)\end{array}$ & $\begin{array}{c}.25 \\
(\mathrm{~N}=45)\end{array}$ & $\begin{array}{c}-.37^{*} \\
(\mathrm{~N}=45)\end{array}$ & $\begin{array}{c}-.17 \\
(\mathrm{~N}=32)\end{array}$ & $\begin{array}{c}-.07 \\
(\mathrm{~N}=40)\end{array}$ & $\begin{array}{c}.31^{*} \\
(\mathrm{~N}=45)\end{array}$ & $\begin{array}{c}.31^{*} \\
(\mathrm{~N}=45)\end{array}$ \\
\hline
\end{tabular}

Note: $+p<.10,{ }^{*} p<.05,{ }^{* *} p<.01,{ }^{* * * *} p<.001$ (two-tailed). Values for Cronbach's alpha are presented diagonally in parentheses. Sample size is presented below means, standard deviations, and Pearson's correlations in parentheses.

Therefore, the use of permutation tests is required (Borgatti, Everett, \& Johnson, 2013; Noreen, 1989). With permutation tests, the standard t-test is computed to compare the means of the two groups but the significance level is generated with permutations. We used UCINET 6 to perform the permutation tests.

Because hypotheses 2a, 2b, and 2c related meeting leaders' position to meeting and team outcomes, they are not subject to the independence issue described above. We thus used standard multiple hierarchical regressions to analyze these data. Group size, gender distribution, and participants' age were integrated in the regression as control variables.

Hypothesis 1a proposed that meeting leaders have a higher degree centrality than meeting participants. Meeting leaders had on average an outdegree centrality of .29. Participants had on average an outdegree centrality of .14.

Over 10,000 permutations, the difference was significant at $P=.00(t=10.42, p=.00)$. That is, in 0 of 10,000 permutations did the outdegree centrality of meeting participants exceed the centrality of meeting leaders. Thus, hypothesis 1a is confirmed.

Hypothesis $1 \mathrm{~b}$ proposed that meeting leaders have a higher betweeness centrality than meeting participants. 
Meeting leaders had on average a weighted betweeness score of 11.26. Participants had on average a weighted betweeness score of 1.60. Over 10,000 permutations, the difference was significant at $P=.00(t=6.97, p=.00)$. That is, in 0 of 10,000 permutations did the weighted betweeness score of meeting participants exceed the score of meeting leaders. Hypothesis $1 \mathrm{~b}$ is thus supported.

Hypothesis 1c proposed that meeting leaders have a lower weighted assortativity than meeting participants. Meeting leaders had on average a weighted assortativity score of 6.33. Participants had on average a weighted assortativity score of 37.30. Over 10,000 permutations, the difference was significant at $P=.00(t=5.03, p$ $=.00$ ). That is, in 0 of 10,000 permutations did the weighted assortativity score of meeting participants exceed the score of meeting leaders. Thus, Hypothesis 1c is confirmed. The results for hypotheses 1a, 1b, and 1c are illustrated in Table 3.

Hypothesis 2a proposed that meeting leaders' position in the meeting network would be related to the number of actions planned during the meeting. The regression shows that the addition of the three network measures significantly added to the prediction of planned actions $(F(6,36)=4.97, p<.01)$. Outdegree centrality had a significantly positive impact on actions planned $(\beta=.42, p<.05)$. By contrast, weighted betweeness $(\beta=.06$, $p>.05)$ and weighted assortativity $(\beta=-.15, p>.05)$ had no significant effect. The control variables group size ( $\beta=-.09, p>.05)$ and gender distribution $(\beta=.10, p>.05)$ did not have a significant impact either. Participants' age $(\beta=-.25, p>$.10) had a marginal significant negative effect. The results for hypothesis $2 a$ are illustrated in Table 4.

Hypothesis $2 \mathrm{~b}$ proposed that meeting leaders' position in the meeting network would be related to team productivity after the meeting. The regression shows that the addition of the three network measures significantly added to the prediction of team productivity $(F(6,23)=4.804, p<.01)$. Weighted assortativity had a significantly negative impact on team productivity $(\beta=-.55, p<.01)$. By contrast, outdegree centrality $(\beta=.31$, $p>.05)$ and weighted betweeness $(\beta=-.56, p>.05)$ had no significant effect. The control variables group size $(\beta=-.24, p>.05)$, gender distribution $(\beta=-.15, p>.05)$, and participants' age $(\beta=.16, p>.05)$ did not have a significant impact either. The results for hypothesis $2 \mathrm{~b}$ are illustrated in Table 5.

Hypothesis 2c proposed that meeting leaders' position in the meeting network would be related to participants' satisfaction with the meeting leader. The regression shows that the addition of the three network measures significantly added to the prediction of team productivity $(F(6,31)=3.06, p<.05)$. Weighted assortativity had a significantly negative impact on meeting satisfaction $(\beta=-.65, p<.01)$. Outdegree centrality had a marginally significant positive influence $(\beta=.44, p>.05)$, whereas weighted betweeness had a marginally significant negative influence $(\beta=-.57, p>.05)$. The control variables group size $(\beta=.18, p>.05)$, gender distribution $(\beta=$ $-.15, p>.05)$, and participants' age $(\beta=.19, p>.05)$ did not have a significant impact. The results for hypothesis 2c are illustrated in Table 6.

\section{Discussion}

Despite the abundance of literature on effective meeting skills and recommended meeting behavior for leaders and managers, empirically contributions are still scarce (e.g., Malouff et al., 2012). Building on early laboratory experiments that examined the structure of communication networks (e.g., Leavitt, 1951; Mulder, 1959; Shaw, 1955), the present study is the first to use social network analysis to explore meeting leaders' behavior in actual team meetings. The study showed that meeting leaders with basic knowledge about moderation techniques take on three different key positions in meeting networks. 1) Having a significantly higher centrality than meeting participants, they are central actors with the highest number of conversational turns. They occupy the central position in the meeting network, and thereby have the most influence on the discussion. 2) With a significantly higher betweeness than meeting participants, they are also brokers who assume a mediating role in the interaction by synchronizing the action and linking participants that are not connected directly. 3) Finally, the significantly lower assortativity compared to meeting participants makes them elicitors who explicitly pay attention to integrating decentral participants into the interaction. Our further analyses show that the roles of meeting leaders have different effects on meeting and team outcomes. The role of central actor is linked to meeting effectiveness so that a meeting leader playing a central part in the meeting and guiding the interaction increases the number of actions that are set to be carried out after the meeting. The role of elicitor is linked to meeting satisfaction and team performance. The more the meeting leader integrates decentral participants the higher participants' satisfaction with the meeting leader's performance and the higher the team productivity after the meeting. 
Table 3. Permutation tests.

\begin{tabular}{ccccc}
\hline & \multicolumn{2}{c}{ Meeting } & & \\
\cline { 2 - 4 } & Leader & Participant & $\mathrm{t}$ & .00 \\
Outdegree centrality & .29 & .14 & $10.28^{* * * *}$ & .00 \\
Weighted beetweeness & $(.09)$ & $(.09)$ & & \\
Weighted assortativity & 11.52 & $(4.45)$ & & $.05^{* * *}$ \\
\hline
\end{tabular}

Note: ${ }^{* * *} p<.001,{ }^{* *} p<.01,{ }^{*} p<.05,+p<.10$ (one-tailed). Standard deviations are presented in parentheses below means.

Table 4. Multiple hierarchical regression analysis with number of planned actions as dependent variable ( $\mathrm{N}=43$ groups).

\begin{tabular}{|c|c|c|c|c|c|c|}
\hline & B & SE (B) & $\beta$ & B & SE (B) & $\beta$ \\
\hline \multicolumn{7}{|l|}{ Step 1: } \\
\hline Group size & -.12 & .16 & -.12 & -.09 & .20 & -.09 \\
\hline Gender distribution & .18 & .16 & .18 & .10 & .14 & .10 \\
\hline Participants' age & -.42 & .16 & $-.42^{*}$ & -.26 & .14 & $-.25+$ \\
\hline $\mathrm{R}^{2}$ & .19 & & & & & \\
\hline $\mathrm{F}$ & $3.07^{*}$ & & & & & \\
\hline \multicolumn{7}{|l|}{ Step 2: } \\
\hline Outdegree centrality & & & & .43 & .20 & $.42^{*}$ \\
\hline Weighted beetweeness & & & & .06 & .25 & .06 \\
\hline Weighted assortativity & & & & -.15 & .15 & -.15 \\
\hline$\Delta \mathrm{R}^{2}$ & & & & .26 & & \\
\hline$\Delta \mathrm{F}$ & & & & $5.74^{* *}$ & & \\
\hline $\mathrm{R}^{2}$ & & & & .45 & & \\
\hline Adj. $R^{2}$ & & & & .36 & & \\
\hline $\mathrm{F}$ & & & & $4.97^{* *}$ & & \\
\hline
\end{tabular}

Note: $+p<.10,{ }^{*} p<.05,{ }^{* *} p<.01,{ }^{* * *} p<.001$ (two-tailed).

Table 5. Multiple hierarchical regression analysis with team productivity as dependent variable ( $\mathrm{N}=30$ groups).

\begin{tabular}{|c|c|c|c|c|c|c|}
\hline & B & SE (B) & $\beta$ & B & SE (B) & $\beta$ \\
\hline \multicolumn{7}{|l|}{ Step 1: } \\
\hline Group SIze & -.48 & .14 & $-.60^{* *}$ & -.19 & .20 & -.24 \\
\hline Gender distribution & -.11 & .14 & -.13 & -.12 & .14 & -.15 \\
\hline Participants' age & .08 & .14 & .10 & .12 & .14 & .16 \\
\hline $\mathrm{R}^{2}$ & .37 & & & & & \\
\hline $\mathrm{F}$ & $4.99^{* *}$ & & & & & \\
\hline \multicolumn{7}{|l|}{ Step 2: } \\
\hline Outdegree centrality & & & & .26 & .19 & .31 \\
\hline Weighted beetweeness & & & & -.38 & .24 & -.56 \\
\hline Weighted assortativity & & & & -.33 & .11 & $-.55^{* *}$ \\
\hline$\Delta \mathrm{R}^{2}$ & & & & .19 & & \\
\hline$\Delta \mathrm{F}$ & & & & $3.29^{*}$ & & \\
\hline $\mathrm{R}^{2}$ & & & & .56 & & \\
\hline Adj. $R^{2}$ & & & & .44 & & \\
\hline $\mathrm{F}$ & & & & $4.80^{* *}$ & & \\
\hline
\end{tabular}

Note: $+p<.10,{ }^{*} p<.05,{ }^{* *} p<.01,{ }^{* * *} p<.001$ (two-tailed). 
Table 6. Multiple hierarchical regression analysis with satisfaction with the meeting leader as dependent variable $(\mathrm{N}=38$ groups).

\begin{tabular}{|c|c|c|c|c|c|c|}
\hline & B & SE (B) & $\beta$ & B & SE (B) & $\beta$ \\
\hline \multicolumn{7}{|l|}{ Step 1: } \\
\hline Group size & -.25 & .19 & -.24 & .19 & .25 & .18 \\
\hline Gender distribution & -.03 & .19 & -.03 & -.16 & .17 & -.15 \\
\hline Participants' age & .03 & .22 & .03 & .21 & .19 & .19 \\
\hline $\mathrm{R}^{2}$ & .06 & & & & & \\
\hline $\mathrm{F}$ & .66 & & & & & \\
\hline \multicolumn{7}{|l|}{ Step 2: } \\
\hline Outdegree centrality & & & & .46 & .25 & $.44+$ \\
\hline Weighted beetweeness & & & & -.55 & .29 & $-.57+$ \\
\hline Weighted assortativity & & & & -.61 & .17 & $-.65^{* *}$ \\
\hline$\Delta \mathrm{R}^{2}$ & & & & .32 & & \\
\hline$\Delta \mathrm{F}$ & & & & $5.22^{* *}$ & & \\
\hline $\mathrm{R}^{2}$ & & & & .37 & & \\
\hline Adj. $R^{2}$ & & & & .25 & & \\
\hline $\mathrm{F}$ & & & & $3.06^{*}$ & & \\
\hline
\end{tabular}

Note: $+p<.10,{ }^{*} p<.05,{ }^{* *} p<.01,{ }^{* * *} p<.001$ (two-tailed).

\subsection{Theoretical Implications}

This study extends theory related to team meetings by providing evidence regarding the role of meeting leaders. We show that they are key players in meetings that are integral to foster good meeting practices and achieve meeting success. Beyond that, we demonstrate that the influence of meeting leaders' behavior exceeds meetings and affects team success. This is of special importance because a pressing concern for managers and meeting leaders is how meetings can be more efficient and how meeting decisions can be translated into team performance (Lehmann-Willenbrock et al., 2013; Rogelberg et al., 2010). Our findings should thus be of interest to researchers studying team leadership and meeting effectiveness.

Meeting leaders are elicitors who have stronger connections to decentral participants. Thus, they encourage contributions from reluctant participants, and thereby promote active meeting behavior. This leads to a positive perception of the meeting leader's performance and has long term effects because it is positively linked to team productivity after the meeting. These findings are in line with previous research that sees active participation of all meeting participants as one of the most important factors in meetings on several levels: 1) It increases group cohesion and consensus between the participants and correlates with higher satisfaction (Malouff et al., 2012; Miranda \& Bostrom, 1999). 2) It helps achieve high meeting citizenship behavior, which includes helping to solve work-related problems and volunteering information (Baran et al., 2011). 3) It reduces groupthink and conflict between participants (Durham, Knight, \& Locke, 1997; Miranda \& Bostrom, 1999). 4) It prevents silence being assumed to mean assent, which can lead to major problems during and following the meeting (Yukl, 2010). 5) It facilitates effective goal attainment when groups work on complex tasks (Bavelas, 1950; Shaw, 1964). Our study extends this research as we show that the role of elicitor has long term effects beyond the scope of meetings. A meeting leader making sure to involve all participants in the meeting interaction increases information-sharing and consensus which leads to reduced conflicts and less work problems. These positive meeting results subsequently pay off in better team work and increased team productivity.

As hypothesized, meeting leaders are also the central actors in meetings who fulfil their task of guiding the meeting process. The effect of this role on meeting and team outcomes, however, is mixed. It is crucial for meeting effectiveness because it increases the number of actions set to be carried out after the meeting. Yet, it has neither an impact on participants' satisfaction with the meeting leader's performance nor on team productivity after the meeting. This is in line with expert observations, which state that giving too much input is an ineffective meeting leadership behavior (Perkins, 2009). Meeting leaders' role requires them to oversee the meeting 
process and not hijack the meeting. Highly central meeting leaders, however, are more likely to emphasize their own opinion and less likely to promote suggestions from the group. Our findings thus provide empirical evidence to the description of the role of meeting leaders as a juggling act. Meeting leaders must constantly move back and forth between taking part in the group work, observing the information-sharing of the participants, and designing the meeting process (Nelson \& MacFadzean, 1998). The meeting leader occupying a central position is helpful for the group to focus on the meeting objectives and make decisions but is also risky if the meeting leader gives too much input. In that case, the meeting is in danger of becoming centralized, which has a negative impact on team performance (Sauer \& Kauffeld, 2013). Hence, it is insufficient for meeting leaders to be central in the interaction. Our study shows that they also need to elicit contributions and ensure evenly distributed participation during the meeting to achieve meeting satisfaction and team success after the meeting. Therefore, meeting leaders need to be aware of the risk of becoming overly central and need to recognize the different roles (observing, designing, and participating) they juggle during the meeting. They need to make sure to structure the meeting and guide the participants to plan further actions and make decisions, but at the same time they need to elicit contributions from all participants and be careful to give them enough space to collaborate.

Finally, meeting leaders are brokers in the meeting network, which matches the recommendations from the literature. They synchronize the interaction and broker interchange between participants who interact little during the meeting. Thereby, they manage the direct exchange of information between meeting participants. This is important for several reasons: 1) Participants have to align their individual mental models and debate different fragments of data before they can focus on the problem at hand (Nelson \& McFadzean, 1998). 2) It fosters creativity as it increases the frequency of creativity-relevant behaviors such as asking questions, clarifying problems, and assessing peer input (Slavin, 1996; Sosik, Kahai, \& Avolio, 1998; Taggar, 2001). However, our results show that the role of broker is not directly linked to meeting and team outcomes. Brokering interchange might thus be a specific action that only has an effect in critical situations. In teams with a positive work atmosphere brokering interaction might not be necessary whereas it might be crucial in teams harboring conflicts. This reasoning is in line with findings demonstrating that synchronizing interaction helps reduce tension and competition between participants (Perkins, 2009).

Finally, this study demonstrates the importance of exploring actual behavior in team meetings. The network approach offers the opportunity to analyze actual interaction and behavior in meetings from a new perspective. It thereby builds on laboratory experiments analyzing communication networks of group discussions and extends prior research such as studies showing the importance of the content of the discussion for meeting success and satisfaction (Kauffeld \& Lehmann-Willenbrock, 2012).

\subsection{Practical Implications}

Six hours per week is the average time an employee spends in meetings per week (Rogelberg et al., 2006). Attending meetings can cost top management executives up to 90 percent and middle management executives up to 60 percent of their weekly working time (Siegert, 2007). With so many working hours taken up, it is clear that meeting effectiveness is highly important. Therefore, it is crucial that meetings are not perceived as unnecessary time-wasters, but instead are seen as a work context in which a team collaborates to achieve better performance by working together (Amabile, 1996; Tobia \& Becker, 1990). Our results show that meeting leaders are key players in meetings. Their meeting behavior fosters effective meeting practices, influences meeting effectiveness, and has lasting effects on team productivity. Therefore, meeting leaders' juggling act of observing and structuring the meeting process needs to be stressed as it is important to identify decentral participants and push for active participation. Organizations need to be aware of the danger of meeting leaders becoming too central to meetings. This may lead to the retreat of meeting participants who might become disinterested and stop contributing (Perkins, 2009). Organizations may thus benefit from educating their executives and meeting leaders on how to lead meetings effectively. Trainings on meeting management should be incorporated into the coaching programs for high-potential employees. The meeting leaders in our study received a two hour briefing about moderation techniques. However, trainings on meeting management should be more extensive and contain the illustration of effective meeting practices to ensure the awareness of meeting leaders' different roles as well as the danger of focusing too much on a single role. For example, meeting leaders should practice eliciting contributions from reserved participants. They should also be trained to manage the juggling act of taking on a central role by guiding the discussion, defining specific actions without stressing their own opinion, and encouraging contributions. 


\subsection{Limitations and Future Research}

Although our study used actual meeting behavior to demonstrate differences between meeting leaders and participants and to link meeting leaders' roles to meeting and team outcomes, it has limitations. First, we used a cross-sectional research design. We only investigated meeting leaders' role in the meeting network of a single meeting, and did not control if the behavior is consistent across several meetings. Given the scarcity of research concerning actual team meetings and interaction networks, however, the present study contributes to the understanding of meeting leaders' behavior and the effects of meeting leaders' roles.

Second, as this was the first step in analyzing meeting leaders' position in meeting networks, we related the network measures to satisfaction with the meeting leader, planned actions during the meeting, and team productivity after the meeting to get an overview over different meeting and team outcomes. However, there are further important outcomes that should be investigated such as participants' evaluation of meeting effectiveness. Future research should built on our findings and explore the influence of meeting leaders' structural position related to dynamic aspects of meetings. Third, our regular work teams came from the manufacturing industry. Thus, our results might not necessarily be generalizable to teams from other lines of work. Moreover, our meeting participants were all German-speaking and mostly male. Although this gender distribution is representative of industrial work, it limits the generalizability of our results.

Our results are a first step to using social network analysis to explore meeting participants' roles and positions in team meetings. In the current study, we focused on the role of meeting leaders. However, the effects of the different roles on meeting and team outcomes are mixed. We thus recommend to further investigate the link between network position and meeting effectiveness. For example, meeting leaders' centrality might be crucial at the beginning when setting the agenda and at the end when defining actions. In the middle of the meeting, however, it might be more important to hold back and concentrate on the tasks of structuring the interaction and eliciting contributions. As mentioned above, the brokering of interchange should be explored in different meeting situations as it might be particularly relevant for teams with negative work atmosphere.

Our results suggest that meetings are a process in which the interactions between the meeting participants are influenced by the meeting leader. For future research, we recommend investigating the influence of different kind of meeting leaders. For example, the structure of supervisor-led meetings might differentiate from meetings with a designated meeting leader. The supervisor might be central at the beginning and the end of the meeting when starting by presenting the agenda and finishing with revisiting the meeting goals. By contrast, a specifically trained meeting leader might be influential over the whole course of the meeting, by summarizing information and brokering interaction. Also, the emergence of leadership in supervisor-less teams should be a topic of future studies. In meetings without a designated leader, a participant might become the informal meeting leader by managing the meeting process, or several team members might take over different facilitation tasks like one focusing on eliciting contributions and another concentrating on summarizing information.

Finally, meeting participants' dependence on the meeting might relate to the strength of the impact of the meeting leader's role in the meeting. Participants who need the information from the meeting to perform well outside the meeting should be more frustrated with an inadequately managed meeting. Thus, the importance of the meeting for the participant's job could be a moderator in the link between the meeting leader's role and meeting outcomes. In the current study, the teams specialized in manufacturing tasks and had the meeting goal of optimizing their work process. Future research should also explore teams from other lines of work with different meeting topics.

\section{Conclusion}

This study took an important step of exploring the interaction structure of team meetings and investigating its effect on meeting and team outcomes. It is the first study to analyze meeting leaders' actual behavior and role in meetings from a network perspective. Our results indicate that meeting leaders are key players in meetings who take on different roles that are crucial for meetings to be successful and the team to be productive. Meeting leaders have a significantly higher outdegree centrality and weighted betweeness and significantly lower assortativity than meeting participants. They are central actors guiding the meeting process, act as brokers fostering interchange between meeting participants, and serve as elicitors encouraging contributions from decentral participants. The role of central actor is linked to numbers of actions set during the meeting. The role of elicitor is related to meeting leader satisfaction and team productivity after the meeting. In terms of managerial implica- 
tions, our findings show the importance of meeting leadership and provide practical recommendations for meeting leaders and supervisors.

\section{Acknowledgements}

The research reported in this article was funded by the German Research Foundation (DFG, Grant No. KA 2256/2-2). Subsets of this data have been examined before (Henschel, Kauffeld, \& Neininger, 2011; Neininger, Lehmann-Willenbrock, Kauffeld, \& Henschel, 2010; Lehmann-Willenbrock, Grohmann, \& Kauffeld, 2012). However, the hypotheses and set of variables examined here have not been published previously. We would like to thank Alexandra Neininger und Angela Henschel for the collection of the data.

\section{References}

Amabile, T. M. (1996). Creativity in Context: Update to the Social Psychology of Creativity. Boulder, CO: Westview.

Bakeman, R., \& Quera, V. (2011). Sequential Analysis and Observational Methods for the Behavioral Sciences. New York: Cambridge University Press. http://dx.doi.org/10.1017/CBO9781139017343

Balkundi, P., \& Harrison, D. A. (2006). Ties, Leaders, and Time in Teams: Strong Inference about Network Structure’s Effects on Team Viability and Performance. Academy of Management Journal, 49, 49-68.

http://dx.doi.org/10.5465/AMJ.2006.20785500

Balkundi, P., \& Kilduff, M. (2006). The Ties That Lead: A Social Network Approach to Leadership. The Leadership Quarterly, 17, 419-439. http://dx.doi.org/10.1016/j.leaqua.2006.01.001

Baran, B. E., Shanock, L. R., Rogelberg, G., \& Scott, C.W. (2011). Leading Group Meetings: Supervisors’ Actions, Employee Behaviors, and Upward Perceptions. Small Group Research, 43, 330-355. http://dx.doi.org/10.1177/1046496411418252

Bass, B. M., \& Stogdill, R. M. (1990). Handbook of leadership. Theory, Research \& Managerial Applications (3rd Ed.). New York, NY: Free Press.

Bauer, V., \& von der Reith, F. (2002). “ ... bei zuviel Mehrarbeit sage ich Nein!” Die Einführung von teilautonomen Arbeitsgruppen auf der betrieblichen Rüttelstrecke. Harburger Beiträge zur Soziologie und Psychologie der Arbeit, 30.

Baumeister, R. F., Vohs, K. D., \& Funder, D. C. (2007). Psychology as the Science of Self-Reports and Finger Movements: Whatever Happened to Actual Behavior? Perspectives on Psychological Science, 2, 396-403. http://dx.doi.org/10.1111/j.1745-6916.2007.00051.x

Bavelas, A. (1950). Communication Patterns in Task-Oriented Groups. Journal of the Acoustical Society of America, 22, 725-730. http://dx.doi.org/10.1121/1.1906679

Bixler, S. (1991). Professional Presence. New York: Putnam.

Bonito, J. A., \& Hollingshead, A. B. (1997). Participation in Small Groups. In B. R. Burleson (Ed.), Communication Yearbook 20 (pp. 227-261). Thousand Oaks, CA: Sage.

Bonito, J. A., \& Sanders, R. E. (2011). The Existential Center of Small Groups: Member's Conduct and Interaction. Small Group Research, 42, 343-358. http://dx.doi.org/10.1177/1046496410385472

Borgatti, S. P. (2006). Identifying Sets of Key Players in a Social Network. Computational \& Mathematical Organization Theory, 12, 21-34. http://dx.doi.org/10.1007/s10588-006-7084-x

Borgatti, S. P., Mehra, A., Brass, D. J., \& Labianca, G. (2009). Network Analysis in the Social Sciences. Science, 323, 892895. http://dx.doi.org/10.1126/science.1165821

Borgatti, S. P., \& Everett, M. G. (1999). Models of Core/Periphery Structures. Social Networks, 21, 375-395. http://dx.doi.org/10.1016/S0378-8733(99)00019-2

Borgatti, S. P., Everett, M. G., \& Johnson, J. C. (2013). Analyzing Social Networks. London: Sage.

Bostrom, R. P., Anson, R., \& Clawson, V. (1993). Group Facilitation and Group Support Systems. In L. Jessup, \& J. Valacich (Eds.), Group Support Systems: New Perspectives (pp. 146-168). New York, NY: Van Nostrand Reinhold.

Brass, D. J. (1984). Being in the Right Place: A Structural Analysis of Individual Influence in an Organization. Administrative Science Quarterly, 29, 518-539. http://dx.doi.org/10.2307/2392937

Brass, D. J., Galaskiewicz, J., Greve, H. R., \& Tsai, W. (2004). Taking Stock of Networks and Organizations: A Multilevel Perspective. Academy of Management Journal, 47, 795-817. http://dx.doi.org/10.2307/20159624

Brodbeck, F. C., Kerschreiter, R., Mojzisch, A., \& Schulz-Hardt, S. (2007). Group Decision Making under Conditions of Distributed Knowledge: The Information Asymmetries Model. Academy of Management Review, 32, 459-479.

http://dx.doi.org/10.5465/AMR.2007.24351441 
Burgess, R. L. (1968). Communication Networks: An Experimental Reevaluation. Journal of Experimental Social Psychology, 4, 324-337. http://dx.doi.org/10.1016/0022-1031(68)90060-7

Burke, C. S., Stagl, K. C., Salas, E., Pierce, L., \& Kendall, D. (2006). Understanding Team Adaptation: A Conceptual Analysis and Model. Journal of Applied Psychology, 91, 1189-1207. http://dx.doi.org/10.1037/0021-9010.91.6.1189

Burt, R. S. (1993). The Social Structure of Competition. In R. Swedberg (Ed.), Explorations in Economic Sociology (pp. 65-103). New York, NY: Russel Sage Foundation.

Burt, R. S. (2004). Structural Holes and Good Ideas1. American Journal of Sociology, 110, 349-399. http://dx.doi.org/10.1086/421787

Carlozzi, C. (1999). Make Your Meeting Count. Journal of Accountancy, 187, 53-55.

Cohen, M. A., Rogelberg, S. G., Allen, J. A., \& Luong, A. (2011). Meeting Design Characteristics and Attendee Perceptions of Staff/Team Meeting Quality. Group Dynamics: Theory, Research, and Practice, 15, 90-104. http://dx.doi.org/10.1037/a0021549

Coleman, J. S. (1990). Foundations of Social Theory. Cambridge, MA: Harvard University Press.

Correll, S. J., \& Ridgeway, C. L. (2003). Expectation States Theory. In J. Delamater (Ed.), Handbook of Social Psychology (pp. 29-51). New York: Springer.

Csardi, G., \& Nepusz, T. (2006). The Igraph Software Package for Complex Network Research. InterJournal 2006, Complex Systems, 1695. http://igraph.org

Cummings, J. N., \& Cross, R. (2003). Structural Properties of Work Groups and Their Consequences for Performance. Social Networks, 25, 197-210. http://dx.doi.org/10.1016/S0378-8733(02)00049-7

Dabbs, J. M., \& Ruback, R. B. (1987). Dimensions of Group Process: Amount and Structure of Vocal Interaction. Advances in Experimental Social Psychology, 20, 123-169. http://dx.doi.org/10.1016/S0065-2601(08)60413-X

DeRue, D. S., Nahrgang, J. D., Wellman, N., \& Humphrey, S. E. (2011). Trait and Behavioral Theories of Leadership: An Integration and Metaanalytic Test of Their Relative Validity. Personnel Psychology, 64, 7-52. http://dx.doi.org/10.1111/j.1744-6570.2010.01201.x

Druskat, V. U., \& Wheeler, J. V. (2003). Managing from the Boundary: The Effective Leadership of Self-Managing Work Teams. Academy of Management Journal, 46, 435-457. http://dx.doi.org/10.2307/30040637

Durham, C. C., Knight, D., \& Locke, E. A. (1997). Effects of Leader Role, Team-Set Goal Difficulty, Efficacy and Tactics on Team Effectiveness. Organizational Behavior and Human Decision Processes, 72, 203-231. http://dx.doi.org/10.1006/obhd.1997.2739

Fox, W. M. (1957). Group Reaction to Two Types of Conference Leadership. Human Relations, 10, 279-289. http://dx.doi.org/10.1177/001872675701000309

Freeman, L. C. (2004). The Development of Social Network Analysis: A Study in the Sociology of Science. Vancouver, BC: Empirical Press.

Friedkin, N. E., \& Slater, M. R. (1994). School Leadership and Performance: A Social Network Approach. Sociology of Education, 67, 139-157. http://dx.doi.org/10.2307/2112701

Goldberg, S. C. (1955). Influence and Leadership as a Function of Group Structure. The Journal of Abnormal and Social Psychology, 51, 119-122. http://dx.doi.org/10.1037/h0042216

Granovetter, M. S. (1973). The Strength of Weak Ties. American Journal of Sociology, 78, 1360-1380. http://dx.doi.org/10.1086/225469

Guetzkow, H., \& Simon, H. A. (1955). The Impact of Certain Communication Nets upon Organization and Performance in Task-Oriented Groups. Management Science, 1, 233-250. http://dx.doi.org/10.1287/mnsc.1.3-4.233

Haynes, M. E. (2006). Meeting Skills for Leaders: A Practical Guide for More Productive Meetings (3rd ed.). Boston, MA: Course Technology.

Henkel, S. (2007). Successful Meetings: How to Plan, Prepare, and Execute Top-Notch Business Meetings. Ocala, FL: Atlantic Publishing.

Hoering, S., Kühl, S., \& Schulze-Fielitz, A. (2001). Homogenität und Heterogenität in der Gruppenzusammensetzung-Eine mikropolitische Studie über Entscheidungsprozesse in der Gruppenarbeit. Zeitschrift für Arbeitsforschung, Arbeitsgestaltung und Arbeitspolitik, 10, 331-351.

Hoppe, B., \& Reinelt, C. (2010). Social Network Analysis and the Evaluation of Leadership Networks. The Leadership Quarterly, 21, 600-619. http://dx.doi.org/10.1016/j.leaqua.2010.06.004

Janicik, G. A., \& Larrick, R. P. (2005). Social Network Schemas and the Learning of Incomplete Networks. Journal of Personality and Social Psychology, 88, 348-364. http://dx.doi.org/10.1037/0022-3514.88.2.348

Jay, A. (1976). How to Run a Meeting. London: Video Arts Limited. 
Kamp, L. (1999). Gruppenarbeit: Betriebs- und Dienstvereinbarungen; Analyse und Handlungsempfehlungen (Bd. 5). Düsseldorf: Hans-Böckler-Stiftung.

Katz, N., Lazer, D., Arrow, H., \& Contractor, N. (2004). Network Theory and Small Groups. Small Group Research, 35, 307-332. http://dx.doi.org/10.1177/1046496404264941

Kauffeld, S. (2006). Kompetenzen messen, bewerten, enwickeln [Measuring, Evaluating, and Developing Competencies]. Stuttgart: Schäffer-Poeschel.

Kauffeld, S., \& Lehmann-Willenbrock, N. (2012). Meetings Matter: Effects of Team Meetings on Team and Organizational Success. Small Group Research, 43, 130-158. http://dx.doi.org/10.1177/1046496411429599

Kelly, J. R., \& Barsade, S. G. (2001). Mood and Emotions in Small Groups and Work Teams. Organizational Behavior and Human Decision Processes, 86, 99-130. http://dx.doi.org/10.1006/obhd.2001.2974

Kilduff, M., Tsai, W., \& Hanke, R. (2005). The Dynamic Stability of Organizational Social Networks. Working Paper, Penn State.

Korsgaard, A., Schweiger, D. M., \& Sapienza, H. J. (1995). Procedural Justice and Changes in Psychological Contacts: A Study of Reenginering Planning. Academy of Management Proceedings, 354-358.

Lavelle, J., Rupp, D., \& Brockner, J. (2007). Taking a Multifoci Approach to the Study of Justice, Social Exchange, and Citizenship Behavior: The Target Similarity Model. Journal of Management, 33, 841-866. http://dx.doi.org/10.1177/0149206307307635

Leach, D. J., Rogelberg, S. G., Warr, P. B., \& Burnfield, J. L. (2009). Perceived Meeting Effectiveness: The Role of Design Characteristics. Journal of Business and Psychology, 24, 65-76. http://dx.doi.org/10.1007/s10869-009-9092-6

Leavitt, H. J. (1951). Some Effects of Certain Communication Patterns on Group Performance. The Journal of Abnormal and Social Psychology, 46, 38-50. http://dx.doi.org/10.1037/h0057189

Lehmann-Willenbrock, N., Allen, J. A., \& Kauffeld, S. (2013). A Sequential Analysis of Procedural Meeting Communication: How Teams Facilitate Their Meetings. Journal of Applied Communication Research, 41, 365-388. http://dx.doi.org/10.1080/00909882.2013.844847

Leung, C. C., \& Chau, H. F. (2007). Weighted Assortative and Disassortative Networks Model. Physica A: Statistical Mechanics and Its Applications, 378, 591-602. http://dx.doi.org/10.1016/j.physa.2006.12.022

Malouff, J. M., Calic, A., McGrory, C. M., Murrell, R. L., \& Schutte, N. S. (2012). Evidence for a Needs-Based Model of Organizational-Meeting Leadership. Current Psychology, 31, 35-48. http://dx.doi.org/10.1007/s12144-012-9129-2

Mangold (2010). INTERACT Quick Start Manual V2.4. Mangold International GmbH (Ed.). www.mangold-international.com

McGuire, R. M. (2011). Weighted Key Player Problem for Social Network Analysis (No. AFIT-OR-MS-ENS-11-13). Air Force Institute of Technology, Wright-Patterson AFB, OH, School of Engineering and Management.

Mesmer-Magnus, J. R., \& DeChurch, L. A. (2009). Information Sharing and Team Performance: A Meta-Analysis. Journal of Applied Psychology, 94, 535-546. http://dx.doi.org/10.1037/a0013773

Mina, E. (2000). The Complete Handbook of Business Meetings. New York: American Management Association.

Miranda, S. M., \& Bostrom, R. P. (1999). Meeting Facilitation: Process versus Content Interventions. Journal of Management Information Systems, 15, 89-114.

Mulder, M. (1959). Power and Satisfaction in Task-Oriented Groups. Acta Psychologica, 16, 178-225. http://dx.doi.org/10.1016/0001-6918(59)90095-2

Mullen, B., \& Salas, C. J. (1991). Effects of Communication Network Structure: Components of Positional Centrality. Social Networks, 13, 169-185. http://dx.doi.org/10.1016/0378-8733(91)90019-P

Nelson, T., \& McFadzean, E. (1998). Facilitating Problem-Solving Groups: Facilitator Competences. Leadership \& Organization Development Journal, 19, 72-82. http://dx.doi.org/10.1108/01437739810208647

Niederman, F., \& Volkema, R. J. (1999). The Effects of Facilitator Characteristics on Meeting Preparation, Set Up, and Implementation. Small Group Research, 30, 330-360. http://dx.doi.org/10.1177/104649649903000304

Noreen, E. W. (1989). Computer Intensive Methods for Testing Hypotheses: An Introduction. New York: Wiley.

Opsahl, T. (2009). Structure and Evolution of Weighted Networks (pp. 104-122). London: University of London (Queen Mary College). http://toreopsahl.com/publications/thesis/; http://toreopsahl.com/tnet/

Perkins, R. D. (2009). How Executive Coaching Can Change Leader Behavior and Improve Meeting Effectiveness: An Exploratory Study. Consulting Psychology Journal: Practice and Research, 61, 298-318. http://dx.doi.org/10.1037/a0017842

Putnam, L. L. (1983). Small Group Work Climates: A Lag-Sequential Analysis of Group Interaction. Small Group Behavior, 14, 465-494. http://dx.doi.org/10.1177/104649648301400405 
Remdisch, S. (1998). Gruppenarbeit in der Automobilindustrie: Die Rolle der Meister und Gruppenleiter. Unveröffentlichte Dissertation, Giessen: Universität Giessen.

Richardson, A. J. (2009). Regulatory Networks for Accounting and Auditing Standards: A Social Network Analysis of Canadian and International Standard-Setting. Accounting, Organizations and Society, 34, 571-588.

http://dx.doi.org/10.1016/j.aos.2008.11.005

Rienks, R., Nijholt, A., \& Barthelmess, P. (2009). Pro-Active Meeting Assistants: Attention Please! Ai \& Society, 23, 213231. http://dx.doi.org/10.1007/s00146-007-0135-0

Rogelberg, S. G., Allen, J. A., Shanock, L., Scott, C., \& Shuffler, M. (2010). Employee Satisfaction with Meetings: A Contemporary Facet of Job Satisfaction. Human Resource Management, 49, 149-172. http://dx.doi.org/10.1002/hrm.20339

Rogelberg, S. G., Leach, D. J., Warr, P. B., \& Burnfield, J. L. (2006). “Not Another Meeting!” Are Meeting Time Demands Related to Employee Well-Being? Journal of Applied Psychology, 91, 83-96. http://dx.doi.org/10.1037/0021-9010.91.1.83

Romano, N. C., \& Nunamaker Jr., J. F. (2001). Meeting Analysis: Findings from Research and Practice. Proceedings of the 34th Annual Hawaii International Conference on System Sciences, 13.

Sarangi, S., \& Unlu, E. (2010). Key Players and Key Groups in Teams: A Network Approach Using Soccer Data. DIW Berlin Discussion Paper, 1053.

Sauer, N. C., \& Kauffeld, S. (2013). Meetings as Networks: Applying Social Network Analysis to Team Interaction. Communication Methods \& Measures, 7, 26-47. http://dx.doi.org/10.1080/19312458.2012.760729

Schultz, B., \& Ketrow, S. M. (1996). Improving Decision Quality in the Small Group: The Role of the Reminder. In R. S. Cathcart, L. A. Samovar, \& L. D. Herman (Eds.), Small Group Communication: Theory and Practice (7th ed., pp. 404410). Dubuque, IA: Brown \& Benchmark.

Schwarz, R. (2012). The Skilled Facilitator Approach. In S. Schuman (Ed.), The IAF Handbook of Group Facilitation: Best Practices from the Leading Organization in Facilitation (pp. 21-34). San Francisco, CA: Jossey-Bass.

Schwarz, R., Davidson, A., Carlson, P., \& McKinney, S. (2005). The Skilled Facilitator Fieldbook: Tips, Tools, and Tested Methods for Consultants, Facilitators, Managers, Trainers, and Coaches. San Francisco, CA: Jossey-Bass.

Scott, J. (2000). Social Network Analysis: A Handbook. London: Sage.

Shaw, M. E. (1955). A Comparison of Two Types of Leadership in Various Communication Nets. The Journal of Abnormal and Social Psychology, 50, 127-134. http://dx.doi.org/10.1037/h0041129

Shaw, M. E. (1964). Communication Networks. Advances in Experimental Social Psychology, 1, 111-147. http://dx.doi.org/10.1016/S0065-2601(08)60050-7

Shelton, M. M., \& Bauer, L. K. (1994). Secrets of Highly Effective Meetings. Thousand Oaks, CA: Corwin.

Siegert, W. (2007). Konferenz mit Ziel und Effizienz: Sparen Sie viel Zeit und Geld! Renningen: Expert.

Sisco, R. (1993). What to Teach Team Leaders. Training, 30, 62-67.

Slavin, R. E. (1996). Research on Cooperative Learning and Achievement: What We Know, What We Need to Know. Contemporary Educational Psychology, 21, 43-69. http://dx.doi.org/10.1006/ceps.1996.0004

Sosik, J. M., Kahai, S. S., \& Avolio, B. J. (1998). Transformational Leadership and Dimensions of Creativity: Motivating Idea Generation in Computer Mediated Groups. Creativity Research Journal, 11, 111-122. http://dx.doi.org/10.1207/s15326934crj1102_3

Sunwolf, \& Frey, L. R. (2005). Facilitating Group Communication. In S. Wheelan (Ed.), The Handbook of Group Research and Practice (pp. 485-509). Thousand Oaks, CA: Sage.

Sunwolf, \& Seibold, D. R. (1999). The Impact of Formal Problem-Solving Procedures on Group Processes, Members, and Task Outcomes. In L. R. Frey, D. S. Gouran, \& M. S. Poole (Eds.), The Handbook of Group Communication Theory and Research (pp. 395-431). Thousand Oaks, CA: Sage.

Taggar, S. (2001). Group Composition, Creative Synergy, and Group Performance. Journal of Creative Behavior, 35, 261286. http://dx.doi.org/10.1002/j.2162-6057.2001.tb01050.x

Tobia, P. M., \& Becker, M. C. (1990). Making the Most of Meeting Time. Training and Development Journal, 34-38.

Uzzi, B. (1996). The Sources and Consequences of Embeddedness for Economic Performance of Organizations: The Network Effect. American Sociological Review, 61, 674-698. http://dx.doi.org/10.2307/2096399

Van Praet, E. (2009). Staging a Team Performance: A Linguistic Ethnographic Analysis of Weekly Meetings at a British Embassy. Journal of Business Communication, 46, 80-99. http://dx.doi.org/10.1177/0021943608325754

Vivacqua, A. S., Marques, L. C., Ferreira, M. S., \& de Souza, J. M. (2008). Information Needs for Meeting Facilitation. In Groupware: Design, Implementation, and Use (pp. 57-64). Springer: Berlin.

Volkema, R. J., \& Niederman, F. (1995). Organizational Meetings Formats and Information Requirements. Small Group Re- 
search, 26, 3-24. http://dx.doi.org/10.1177/1046496495261001

Wasserman, S., \& Faust, K. (1994). Social Network Analysis: Methods and applications. New York: Cambridge University Press. http://dx.doi.org/10.1017/CBO9780511815478

Wayne, S. J., Shore, L M., Bommer, W. H., \& Tetrick, L. E. (2002). The Role of Fair Treatment and Rewards in Perceptions of Organizational Support and Leader Member Exchange. Journal of Applied Psychology, 87, 590-598. http://dx.doi.org/10.1037/0021-9010.87.3.590

Westphal, J. D., Seidel, M.-D., \& Stewart, K. S. (2001). Second-Order Imitation: Uncovering Latent Effects of Board Network Ties. Administrative Science Quarterly, 46, 717-747. http://dx.doi.org/10.2307/3094829

Wheelan, S. A., \& Johnston, F. (1996). The Role of Informal Member Leaders in a System Containing Formal Leaders. Small Group Research, 27, 33-55. http://dx.doi.org/10.1177/1046496496271002

Yrle, A. C., Hartman, S., \& Galle, W. P. (2002). An Investigation of Relationships between Communication Style and Leader-Member Exchange. Journal of Communication Management, 6, 257-268. http://dx.doi.org/10.1108/13632540210807099

Yukl, G. (2010). Leadership in Organizations (7th ed.). Upper Saddle River, NJ: Pearson.

Zaccaro, S. J., Rittman, A. L., \& Marks, M. A. (2001). Team Leadership. Leadership Quarterly, 12, 451-483. http://dx.doi.org/10.1016/S1048-9843(01)00093-5 